\title{
Peak flow rate records in the diagnosis of occupational asthma due to colophony
}

\author{
P SHERWOOD BURGE, I M O'BRIEN, AND M G HIARRIES \\ From the Department of Clinical Immunology, Cardiothoracic Institute, Brompton Hospital, \\ London SW3 6HP, UK
}

\begin{abstract}
Peak expiratory flow rate (PEFR) has been measured hourly from waking to sleeping in 29 workers with respiratory symptoms exposed to the fumes of soft soldering fluxes containing colophony (pine resin). Thirty-nine records of mean length 33 days have been analysed, and the results compared with the occupational history and bronchial provocation testing in the same workers. From plots of daily mean, maximum, and minimum PEFR, recurring physiological patterns of asthma emerge. The most common pattern is for asthma to increase with each successive working day. Some workers have an equivalent deterioration each working day.

Regular recovery patterns taking one, two, and three days are described. The combination of a three-day recovery pattern and a late asthmatic reaction on Monday results in Monday being the best day of each week. Assessment of these records has shown them to be specific and sensitive, provided the worker was not taking corticosteroids or sodium cromoglycate during the period of the record and that bronchodilator usage was kept constant on days at home and at work. The results of the PEFR records correlate well with bronchial provocation testing, and provide a suitable alternative to this for the diagnosis of mild to moderate occupational asthma. The records are of particular use for screening symptomatic workers whose symptoms appear unlikely to be related to work.
\end{abstract}

An occupational cause for wheeze and breathlessness is often missed. Reasons for this include the lack of readily applicable diagnostic tests and a lack of understanding of the basic patterns of occupational asthma, as seen at work rather than in the laboratory. The Monday morning symptoms of stage I byssinosis provide the only clearly described pattern of occupational airways disease. It is so characteristic that the diagnosis can be based on the history alone (Schilling, 1956). Symptoms most severe on the first day of the working week are seen in a wide range of diseases where fever is prominent, and wheeze is often present. These include metal fume fever (Greenhow, 1862), humidifier fever (Pickering et al, 1976), meat wrapper's asthma (Sokol, 1973), feather picker's asthma (Plessner, 1960), and grain fever (Williams et al, 1964; Kleinfeld et al, 1968).

Measurement of lung function before and after a working shift has formed the basis of objective tests for occupational asthma in the work situa- tion. This has often been disappointing. Schoenberg and Mitchell (1975) measured FEV $_{1}$ and $\mathrm{MEF}_{50}$ in workers with lower respiratory symp- 3 . toms exposed to formaldehyde fumes. The mean fall in $\mathrm{FEV}_{1}$ was $1.1 \%$ over a Monday shift with a slight increase on a Friday shift. $\mathrm{MEF}_{50}$ fell $\mathrm{O}$ $4.3 \%$ on the Monday and rose on the Friday. Gandevia (1963) found a mean decrease in $\mathrm{FEV}_{1}$ o of 0.181 in 15 workers exposed to isocyanate fumes over three working days. Fawcett et al or (1978) showed a mean fall in $\mathrm{FEV}_{1}$ of $4 \%$ in a N group of byssinotics in a coarse cotton mill. These $\mathrm{\omega}_{\mathrm{\omega}}$ studies illustrate the difficulty in confirming an $\omega$ occupational history this way. Burge et al (1979b) were able to show a fall in $\mathrm{FEV}_{1}$ of $10 \%$ or more $\frac{2}{\mathbb{D}}$ over at least one of three work shifts in a third of $\stackrel{\oplus}{\rightleftharpoons}$ a group of workers in an electronics factory, all of whom had symptoms highly suggestive of $\overline{0}$ occupational asthma. Most workers with colo- $\vec{\Phi}$ phony sensitivity have immediate asthmatic $\stackrel{?}{\mathbb{D}}$ reactions on bronchial provocation testing (Burge $\frac{\varrho}{\sigma}$ et al, 1978), which may explain these better 
results. Objective evidence, however, was still not obtained in two-thirds of the symptomatic workers.

Occupational-type provocation testing has been extremely useful in recording new causes of occupational asthma (Pepys and Hutchcroft, 1975; Burge and Pepys, 1979). It is timeconsuming and necessitates hospital admission for an average of two weeks. A negative provocation test may result from a failure to expose an individual to the material causing his symptoms or failure to produce the same conditions as at work. False-positive reactions can occur if irritant concentrations of fumes and dust are reached.

This study represents an attempt to do four things: to provide objective evidence in the electronics industry for occupational respiratory symptoms suggestive of asthma; to investigate the patterns of asthmatic reactions seen at work and at home; to evaluate the use of the records of PEFR for diagnosis; and to compare the results obtained with those from the history and bronchial provocation testing.

Each worker has been studied using an occupational history, bronchial provocation testing, and a record of peak expiratory flow rate at home and work for at least two weeks.

Previous work has shown that the main sensitising agent in the electronics industry using fluxcored solder is colophony, an extract of pine resin (Burge et al, 1978). Some workers in the electronics industry have also been sensitised to toluene di-isocyanate fumes liberated when polyurethane-coated wires are soldered or tinned (Paisley, 1969; Pepys et al, 1972).

\section{Methods}

We studied workers who had had bronchial provocation testing by exposure to solder-flux fumes in hospital and had kept a record of their PEFR at home and at work for at least two weeks. Workers were studied from five separate electronics factories. All manufactured radios or television; one factory was not using mass production techniques. Atmospheric monitoring of colophony levels in two of the factories had shown levels of exposure below the threshold limit value on personal monitors. Workers with the most severe symptoms had already left work before they were investigated and were therefore excluded.

Each worker was given either a Wright's peak flow meter (Wright and McKerrow, 1959), a Wright's peak flow gauge (Gregg, 1964), or occasionally a Vitalograph pulmonary monitor
(Haydu et al, 1976). They were shown how to use the meter and read the result. They were asked to perform at least three blows on each occasion and to record the best result. The best two results had to be within $20 \mathrm{l} / \mathrm{min}$ of each other (or one division on a pulmonary monitor). They were asked to record their PEFR every hour from waking to sleeping.

Bronchial provocation testing was carried out in hospital with a single exposure on each day (Burge et al, 1978). The provocation test was called negative if there was a fall in $\mathrm{FEV}_{1}$ of less than $15 \%$ compared with control after exposure to solder-flux fumes for one hour on two successive days.

\section{ANALYSIS OF RESULTS OF THE PEAK EXPIRATORY} FLOW RATE RECORDS

The basis of the interpretation was the comparison of recordings taken when away from work with those taken at work. Since a reaction resulting from work often continues or starts after work, all readings taken within 24 hours of starting work were classed as "at work" and compared with readings taken on days with no work exposure at all. For each day the mean, maximum, and minimum PEFR was plotted, this being the easiest way to visualise the significance of recordings. The distribution of the daily values about the daily mean was usually skewed with a greater number of lower readings than would be expected in a normal distribution. Some records were plotted using the daily median rather than the mean. The visual effects were similar, the median being usually about $10 \mathrm{l} / \mathrm{min}$ above the mean. Because of their visual similarity mean values have been used as they are simpler to calculate.

Thirty-nine records were obtained from 29 workers. The mean length of the records was $32 \cdot 6$ days $(14-78)$.

\section{Results}

The physiological pattern seen in the PEFR records have been classed as those occurring from hour to hour within a day (the hourly pattern), those occurring from day to day in the same working week (the daily pattern), and those occurring from week to week (the weekly pattern).

The hourly patterns showed the immediate and late asthmatic reactions seen on bronchial provocation testing. An example of an immediate reaction is shown in fig 1 . The drop in PEFR started within 15 minutes of coming to work on Monday morning. The PEFR continued to fall 


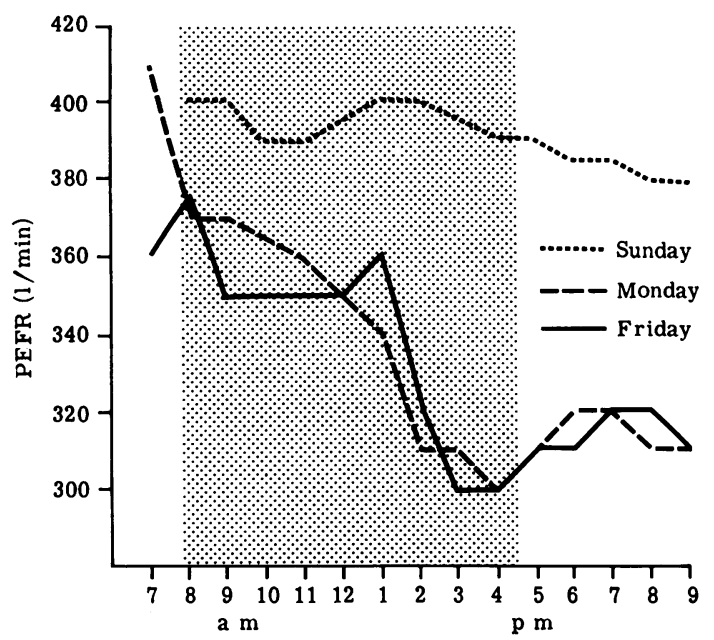

Fig 1 Plot of hourly PEFR of a wiring and soldering line supervisor. Period at work on Monday and Friday is shaded. Sunday record is taken at home. It shows a drop in peak flow within 15 minutes of coming to work on Monday, which continues to fall until leaving work. By Friday a morning dip has occurred, masking initial fall in PEFR. This record shows equivalent deterioration each working day.

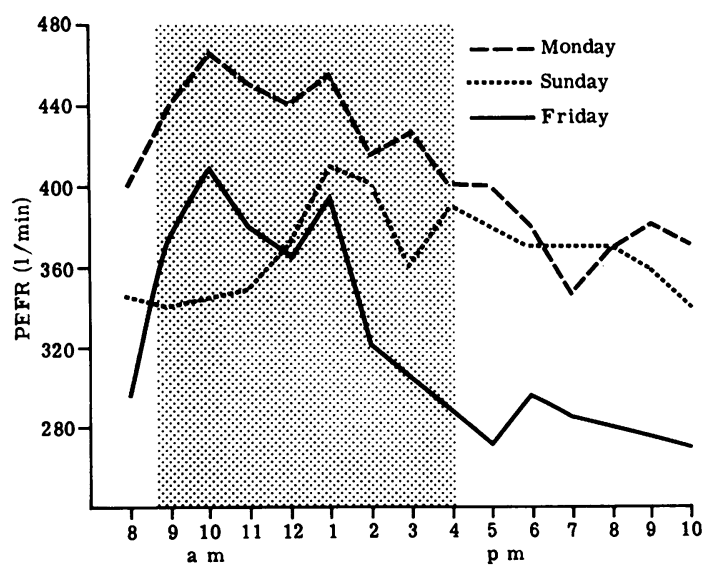

Fig 2 Plot of hourly PEFR in a production line inserter. Sunday record at home shows a morning dip and exaggerated "normal" diurnal variation. Morning dip has lessened by Monday morning but a late asthmatic reaction starts just before leaving work. By Friday of same working week morning dip and late asthmatic reaction are pronounced. This record shows progressive deterioration with work exposure and a three-day recovery pattern (see fig 4). throughout the day, persisted in the evening, and recovered overnight. On provocation testing a nine and a half minute exposure to flux cored solder produced an immediate asthmatic reaction that resolved after two hours. The reaction was blocked by sodium cromoglycate pretreatment.

Figure 2 shows a late asthmatic reaction at work. This woman had a pronounced morning dip followed by initial improvement at work. Her asthma usually started shortly before leaving work in the evening, but sometimes only after leaving work. The first day at work after a break produced a much smaller reaction than on subsequent days. Her PEFR was often lower on coming to work than when leaving.

DAILY PATTERNS OF PEAK EXPIRATORY FLOW RATE

The patterns seen depended on the cumulative effect of repeated exposures and on the time taken for recovery. Provided recovery was substantial within two to three days a regular weekly pattern resulted.

Repeated daily exposures may result in an equivalent deterioration each day (fig 3 ), a greater deterioration with each day's exposure (fig 4), or a deterioration on the first working day with lesser reactions on subsequent days (fig 5). Recovery can be complete on the day after exposure

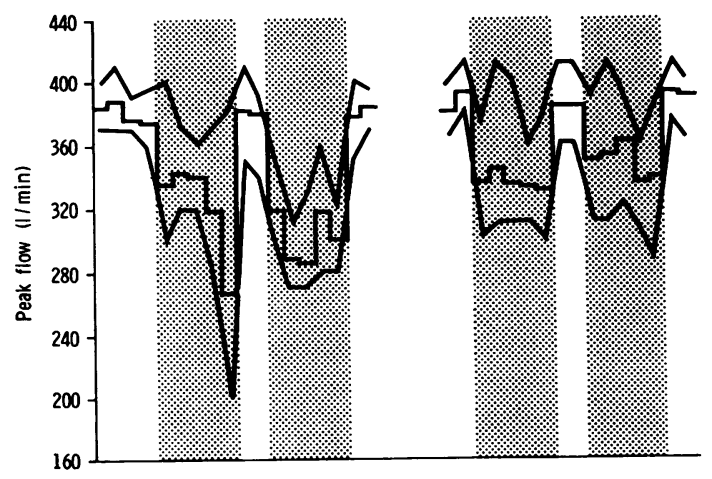

Fig 3 Plot of daily maximum (upper line), mean (centre line), and minimum (lower line) PEFR in a wiring and soldering production line supervisor (same worker as in fig 1). Days at work are shaded, days wholly at home have a plain background. Each horizontal bar of the centre record represents one day. Record shows a small diurnal variation before work at start of record. First week shows clear deterioration with lowest readings on last working day, followed by complete recovery on first day off work. Recovery pattern persists throughout record, but subsequent weeks show equivalent deterioration on each working day. 


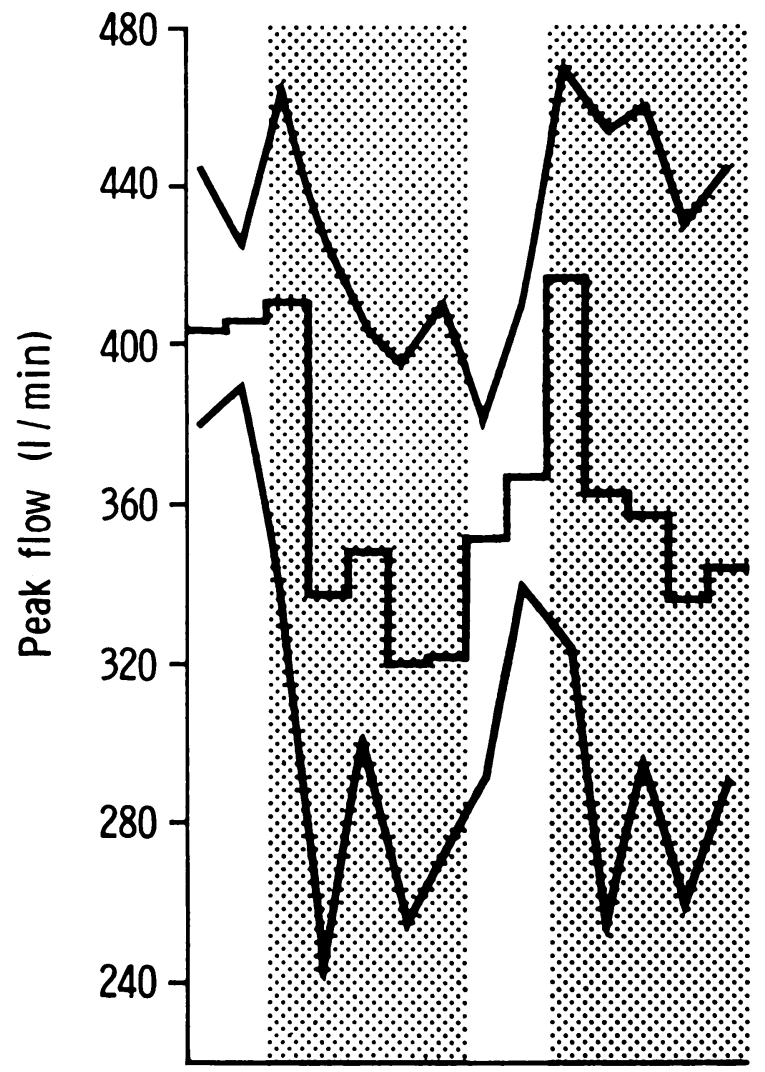

Fig 4 Plot of maximum, mean, and minimum daily PEFR in a production line inserter (same worker as fig 2). Record shows progressive deterioration with cach working day in both weeks. Recovery takes three days (a "Monday best" record).

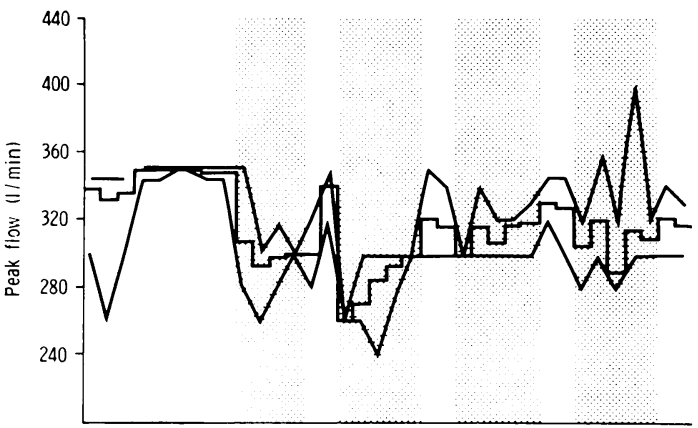

Fig 5 Plot of maximum, mean, and minimum daily PEFR in a coil winder who does no soldering or tinning. It shows: Working week 1 -equivalent deterioration each working day; first weekend-two day recovery; working week 2-Monday worst, with progressive improvement; second weekend-partial one-day recovery; working week 3-no definite change; third weekend-partial one-day recovery; and working week 4-small irregular deterioration. Continued exposure has produced weeks with less deterioration than seen in first two working weeks.

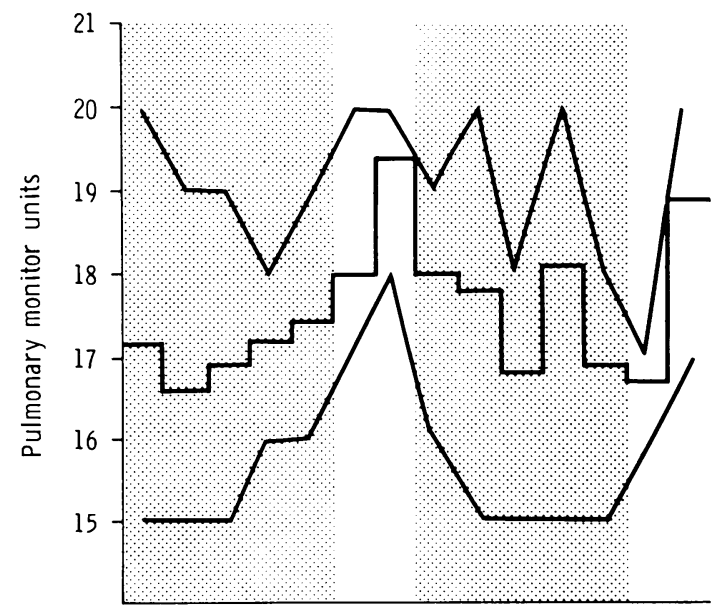

Fig 6 Plot of daily maximum, mean, and minimum PEFR in a nibbling machine operator in an electronics factory (no soldering done). Readings have been made on a Vitalograph pulmonary monitor. Record shows a two-day weekend recovery. 


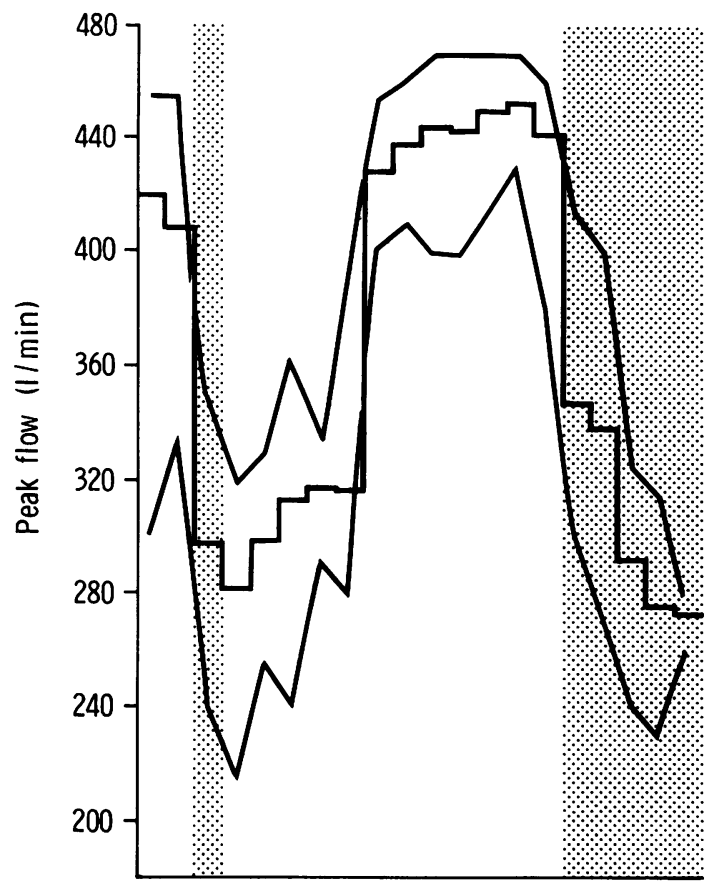

Fig 7 Plot of daily maximum, mean, and minimum $P E F R$ in an electronics tester who does no soldering. Worker returned to work after a three-week absence at start of record. One day's work exposure resulted in asthma lasting six days. Recorded working week shows progressive deterioration with each working day.

(fig 3) or take two or three more days (figs 4 and 6). The combination of a three-day recovery pattern and a late reaction on the first day at work results in a weekly pattern with the first working day the best of the week (fig 4).

Week by week changes were seen much more commonly in workers exposed to isocyanate fumes and are described separately (Burge et al, 1979a). In only two electronics workers sensitive to

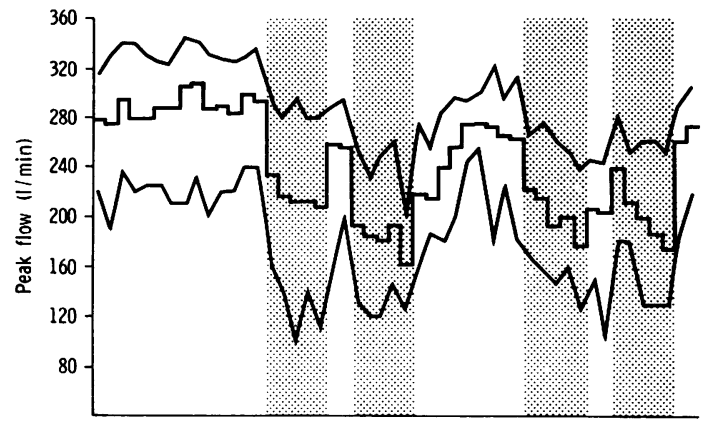

Fig 8 Plot of daily maximum, mean, and minimum $P E F R$ in an electronics coder who does no soldering. It shows an increased diurnal variation during initial period off work, followed by: working weeks 1-4progressive daily deterioration; first weekendpartial one-day recovery; nine days off work-fiveday recovery, and second weekend (between working weeks 3 and 4)-three-day recovery. Record shows progressive weekly deterioration for last two working weeks.

colophony was the start of recovery delayed for more than three days after stopping work (fig 7). Figure 8 shows progressive weekly deterioration, and fig 5 progressive weekly improvement.

The frequency of the daily patterns is shown in table 1. One hundred and one working-weeks were recorded in the 22 workers eventually assessed as having work-related asthma. Progressive deterioration with each work-day was the most common pattern seen, and was present in $46 \%$ of the weeks at work. Weeks with an equivalent deterioration each working day, and with maximal deterioration on the first workingday, were much less common. There were no definite deterioration patterns in $33 \%$ of weeks at work. Specific deterioration patterns were seen only in four of 25 weeks at work recorded in the seven workers judged not to have occupational asthma.

Table 1 Specific deterioration and recovery patterns seen in workers with occupational asthma and workers without work-related symptoms. Percentages of total recorded weeks. (For description of the patterns, see text)

\begin{tabular}{|c|c|c|c|c|c|c|c|c|}
\hline & \multicolumn{3}{|c|}{ Daily deterioration patterns } & \multirow{2}{*}{$\begin{array}{l}\text { Total } \\
\text { recorded } \\
\text { weeks at } \\
\text { work }\end{array}$} & \multicolumn{3}{|c|}{ Weekend recovery patterns } & \multirow{2}{*}{$\begin{array}{l}\text { Total } \\
\text { recorded } \\
\text { weekends }\end{array}$} \\
\hline & $\begin{array}{l}\text { Each work-day } \\
\text { equivalent }\end{array}$ & $\begin{array}{l}\text { First work-day } \\
\text { worst }\end{array}$ & $\begin{array}{l}\text { Progressive } \\
\text { deterioration } \\
\text { (Friday worst) }\end{array}$ & & Saturday & Sunday & Monday & \\
\hline Work-related asthma & 13 & 8 & 46 & 101 & 24 & 23 & 6 & 101 \\
\hline $\begin{array}{l}\text { Respiratory symptoms not } \\
\text { work related }\end{array}$ & 4 & 0 & 12 & 25 & 5 & 8 & 0 & 25 \\
\hline
\end{tabular}




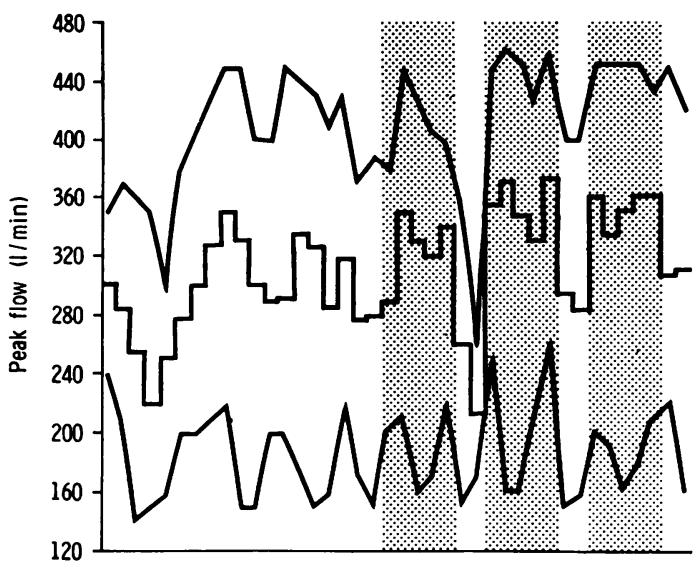

Fig 9 Plot of daily maximum, mean, and minimum $P E F R$ in a wirer and solderer showing a pronounced diurnal variation throughout with improvement during each working week and deterioration at each weekend, suggesting a domestic cause for her symptoms.

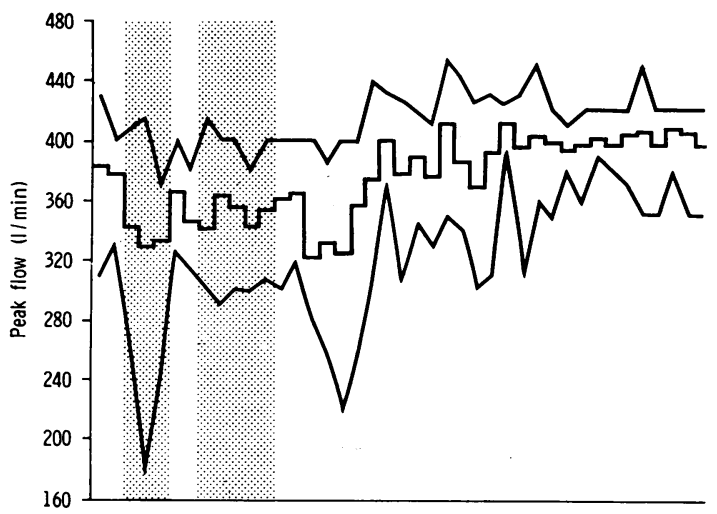

Fig 10 Plot of daily maximum, mean, and minimum PEFR in a wirer and solderer. Record shows: working week 1-equivalent deterioration each working day; first weekend-no definite recovery; working week 2no definite deterioration; and period off workstable mean PEFR and reduction of diurnal swings after 18 days. This represents an equivocal record.

Specific recovery patterns were seen in $53 \%$ of periods away from work in the affected workers, compared with $12 \%$ in the unaffected. Recovery taking one day was as common as recovery taking two days, but recovery taking three days was much less common.

We classified each of the records into one of four categories, without knowledge of the subject's symptoms or challenge test:
1. Work-related asthma; if specific deterioration or recovery patterns were seen on at least three of every four weeks worked.

2. Non-work-related asthma; if asthma was present with less than one in four weeks showing specific deterioration or recovery patterns (fig 9).

3. An equivocal record; if specific deterioration or recovery patterns were seen in $26-74 \%$ of weeks recorded (fig 10).

4. An inadequate record; if any of the following were present:

Very few days away from work, with no periods greater than one day away from work.

Frequent changes of treatment, making the effect of treatment difficult to separate from the effect of work.

Records showing continuing deterioration or improvement throughout, the records not being long enough for these to level out.

Records where there had been no exposure to the suspected aetiological agent during the period of the records.

The results of these assessments are shown in table 1 .

The final assessment of each worker was made from the history and the effects of subsequent exposure at work after provocation testing. This was positive in 22 workers and negative in seven. The PEFR records had not been analysed when these assessments were made, but the results of the provocation testing may have influenced the final assessment. The workers were divided into those with a strong history of occupational asthma with symptoms on at least three days each week, those with symptoms on two or fewer days each week, and those whose history did not suggest occupational asthma. Table 2 shows the results of the bronchial provocation tests and the subjective assessments of peak flow records. Positive provocation tests were present in 24 workers; 23 of these had immediate asthmatic reactions with some late fall in $\mathrm{FEV}_{1}$. The late asthmatic component was strongly correlated with the degree of immediate reaction so the presence or absence of a late asthmatic reaction was mostly dependent on the technique of provocation. Only one worker had a late asthmatic reaction alone.

The proportion of equivocal assessments increased greatly when cromoglycate or corticosteroids were being taken during the recording, and so these records have been analysed separately.

The sensitivity (the number of workers with a positive test divided by the total number of workers assessed as having work-related asthma) and the specificity (the number of workers with a 
Table 2 Subjective assessment of PEFR records, and maximum diurnal variation in peak flow records

\begin{tabular}{|c|c|c|c|c|c|c|c|c|c|}
\hline \multirow[b]{2}{*}{$\begin{array}{l}\text { History of } \\
\text { work-related asthma }\end{array}$} & \multirow[b]{2}{*}{ No } & \multirow[b]{2}{*}{$\begin{array}{l}\text { Challenge } \\
\text { positive }\end{array}$} & \multicolumn{4}{|l|}{ Assessment } & \multicolumn{3}{|c|}{ Maximum diurnal variation in peak flow } \\
\hline & & & $\begin{array}{l}\text { Work-related } \\
\text { asthma }\end{array}$ & Equivocal & $\begin{array}{l}\text { Non-work- } \\
\text { related } \\
\text { asthma }\end{array}$ & Inadequate & $>50 \%$ & $30-49 \%$ & $<30 \%$ \\
\hline $\begin{array}{l}\text { Three or more days } \\
\text { each week - no drugs }\end{array}$ & 12 & 12 & 9 & 2 & & 1 & 2 & 9 & 1 \\
\hline $\begin{array}{l}\text { Three or more days } \\
\text { each week-taking } \\
\text { corticosteroids or } \\
\text { cromoglycate }\end{array}$ & 14 & 14 & 5 & 7 & 1 & 1 & 5 & 5 & 4 \\
\hline $\begin{array}{l}\text { Two or fewer days } \\
\text { each week-no drugs } \\
\text { Taking cromoglycate }\end{array}$ & $\begin{array}{l}4 \\
1\end{array}$ & $\begin{array}{l}3 \\
1\end{array}$ & $\begin{array}{l}1 \\
1\end{array}$ & 1 & & 2 & & 1 & 4 \\
\hline $\begin{array}{l}\text { Not suggestive- } \\
\text { no drugs } \\
\text { Taking corticosteroids }\end{array}$ & $\begin{array}{l}7 \\
1\end{array}$ & $\begin{array}{l}1 \\
1\end{array}$ & & 1 & $\begin{array}{l}5 \\
1\end{array}$ & 1 & 1 & 2 & 5 \\
\hline
\end{tabular}

Table 3 Sensitivity and specificity of bronchial provocation testing with flux-cored solder, and the subjective assessment of PEFR records at work

\begin{tabular}{lllll}
\hline & $\begin{array}{l}\text { Sensitivity } \\
\%\end{array}$ & $\begin{array}{l}\text { Specificity } \\
\%\end{array}$ & $\begin{array}{l}\text { Potential } \\
\text { number of } \\
\text { positive } \\
\text { assessment assessment }\end{array}$ \\
\hline $\begin{array}{l}\text { number of } \\
\text { negative }\end{array}$ \\
\hline $\begin{array}{l}\text { Bronchial provocation } \\
\text { testing }\end{array}$ & 100 & 71 & 19 & 7 \\
$\begin{array}{l}\text { Peak expiratory flow } \\
\text { rate record-worker } \\
\text { not taking } \\
\text { corticosteroids or } \\
\text { cromoglycate }\end{array}$ & 77 & 100 & 15 & 7 \\
$\begin{array}{l}\text { Peak expiratory flow } \\
\text { rate record-worker } \\
\text { taking cromoglycate } \\
\text { or corticosteroids }\end{array}$ & 42 & - & 12 & 0 \\
\hline
\end{tabular}

negative test divided by the total number of workers assessed as not having work-related asthma) were calculated for the bronchial provocation testing and the analysis of PEFR records. The results are shown in table 3 . All inadequate PEFR records are omitted.

\section{Discussion}

The workers studied here were selected because they had been referred to us at the Brompton Hospital. They were all able to continue exposure at work for some weeks while the PEFR recordings were made. This necessarily excluded all those with the most severe occupational asthma.

There are several sources of error in the recordings of PEFR. Errors due to variation between meters and between instructors (Fairbairn et al, 1962) are eliminated as readings are only being compared on one meter and one subject. Varia- tion within each meter, errors caused by sub- $\subseteq$ maximal effort, and incorrect recording of the ${ }^{\mathbb{D}}$ results are likely to be the same at home and at $\vec{\varphi}$ work and therefore should not bias the results. $\widehat{~}$ The main error is likely to be due to submaximalo effort. The workers were asked to continue recordings until the best two were within $201 / \mathrm{min} \frac{}{5}$ of each other to reduce this error. It is obviously possible for the records to be fabricated but this is $\Phi$ unlikely to have occurred often, as consistent and previously unreported physiological patterns were $\stackrel{\circ}{\circ}$ seen throughout the records. Occasional readings were missing from most records and these would probably have been filled in if the records had: been fabricated.

The true PEFR will vary due to normal diurnal variation, exposure to solder flux fumes at work, $\underset{i}{\dot{x}}$ and other factors, such as exercise, other aller- 3 gens, and respiratory infection. The solder flux fumes are likely to vary greatly at work from 3 day to day, particularly when the weather is cold $\circ$ or wet when ventilation is usually much less effective as windows are shut. These variations $\underset{0}{\square}$ may explain why the patterns seen often varied from week to week. Nevertheless, recurrent $N$ patterns were often seen. The physiological $N$ response to the fumes at work are superimposed $N$ on to the normal diurnal variation. Many workers $\omega$ recorded their lowest PEFR on waking. This morning dip became less with recovery.

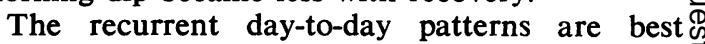
classified according to the day of maximal symp-? toms. By far the commonest pattern in this study was of increasing symptoms throughout the work- $\mathbb{D}$ ing week, Friday being the worst day of a normal $\stackrel{\frac{\Omega}{\odot}}{\circ}$ five-day week. This may be due to increasing $\varrho$ day-to-day sensitivity or to a lower starting PEFR 
or both. Symptoms that were equally severe on each working day constituted the other main pattern seen. This was usually associated with immediate asthmatic reactions and a rapid recovery.

There were very few workers with a Monday morning asthma pattern. No worker had this consistently, suggesting that when it occurred it may have been due partly to heavy exposure on that day. The Monday morning pattern usually occurs in diseases where previous exposure is unnecessary and probably has a non-allergic mechanism. It is perhaps caused by activation of the alternate complement pathway with mediator release via $\mathrm{C} 3 \mathrm{a}$ and $\mathrm{C} 5 \mathrm{a}$. Histamine release via this mechanism may show tachyphylaxis accounting for the subsequent improvement despite continued exposure. However, an Arthus reaction elicited by a large dose of antigen may not be repeatable for several days (Opie, 1924). This is due to a reduction of antibody by the initial reaction that may take several days to return to the concentration required to produce another reaction. A similar mechanism could occur in occupational asthma.

A diurnal variation in PEFR was often considerable. Eight of the records showed a variability greater than $50 \%$, a factor associated with respiratory arrest in asthma (Hetzel et al, 1967). Each worker made an average of about 1500 PEFR measurements, of which the best 500 were recorded. When they are plotted sequentially it is very difficult to see physiological patterns emerging (Siracusa et al, 1978). The daily plots of mean, maximum, and minimum PEFR have provided an easy means for subjective visual assessment. The criteria adopted for the diagnosis of workrelated asthma were strict, needing a definite work-related pattern on three of every four weeks of work. This resulted in $100 \%$ specificity but reduced sensitivity, especially when the worker was taking sodium cromoglycate or corticosteroids at work. Some workers had work-related asthma on occasional days at work only. This may have been associated with the failure of an extraction fan, closing of windows, or a move in work position. Sodium cromoglycate has protected most patients exposed to colophony fumes on bronchial provocation testing (Burge et al, 1978). Apparently the protective effect can be overcome, particularly when the concentration of fumes is high. This may convert a worker with a regular weekly pattern to somebody with asthma only on occasional days, making the causal association with work more doubtful. Initially, some workers took more treatment on days at work than on days at home, sometimes masking the work effect. It is therefore necessary to keep bronchodilator doses constant on days at work and home in a study such as this. Most of the workers were taking bronchodilators during the time of the recording, and they have not obscured the physiological patterns.

We have now performed bronchial provocation testing with flux-cored solder and colophony fumes in more than 60 workers. The upper limit of exposure is somewhat arbitrary, but so far our maximum exposure is an hour's soldering with flux-cored solder or 15 minutes heating of colophony. The 15-minute exposure to colophony has probably caused a few non-specific reactions in workers with severe asthma from other causes. All workers in this study with a final assessment of occupational asthma had a bronchial provocation test to colophony fumes. There were two reactors in those without occupational asthma; one of these soldered regularly at home as well as having childhood asthma. It is quite possible that he was sensitised by his domestic exposure.

Regular recording of PEFR at home and work has proved to be a very specific and reasonably sensitive method of diagnosing occupational asthma due to solder-flux fumes and a suitable alternative to bronchial provocation testing in workers with mild to moderate work-related symptoms. Those with severe symptoms are better diagnosed by bronchial provocation testing if a specific aetiological diagnosis is required. In this situation the exposure can be short and controlled unlike the long, uncontrolled exposures at work.

This paper forms part of an MSc thesis in occupational medicine at the London School of Hygiene and Tropical Medicine.

\section{References}

Burge, P S, Harries, M G, O'Brien, I M, and Pepys, J (1978). Respiratory disease in workers exposed to solder flux fumes containing colophony (pine resin). Clinical Allergy, 8, 1-14.

Burge, P S, O'Brien, I M, and Harries, M G (1979a). Peak flow rate records in the diagnosis of occupational asthma due to isocyanates. Thorax, 34, 317-323.

Burge, P S, and Pepys, J (1979). Occupational type bronchial provocation testing. Allergologie, 2, 7-12.

Burge, P S, Perks, W, O'Brien, I M, Burge, A, Hawkins, R, Brown, D, and Green, $M(1979 b)$. Occupational asthma in an electronics factory. A case control study to evaluate aetiological factors. Thorax, 34, 300-307.

Fairbairn, A S, Fletcher, C M, Tinker, C M, and Wood, C H (1962). A comparison of spirometric 
and peak expiratory flow measurements in men with and without chronic bronchitis. Thorax, 17, 168-174.

Fawcett, I W, Merchant, J A, Simmonds, S P, and Pepys, J (1978). The effect of sodium cromoglycate, beclomethazone diproprionate, and salbutamol on the ventilatory response to cotton dust in mill workers. British Journal of Diseases of the Chest, 72, 29-38.

Gandevia, B (1963). Studies of ventilatory capacity and histamine response during exposure to isocyanate vapour in polyurethane foam manufacture. British Journal of Industrial Medicine, 20, 204-209.

Greenhow, E H (1862). On brass-founders' ague. Medico Chirurgical Transactions, 45, 177-187.

Gregg, I (1964). The measurement of peak expiratory flow rate and its application in general practice. Journal of the College of General Practitioners, 7, 199-214.

Haydu, S P, Chapman, T T, and Hughes, D T D (1976). Pulmonary monitor for assessment of airways obstruction. Lancet, 2, 1225-1226.

Hetzel, M R, Clark, T J H, Branthwaite, M A (1977). Asthma: analysis of sudden deaths and ventilatory arrests in hospital. British Medical Journal, 1, 808811

Kleinfeld, M, Messite, J, Swencicki, R E, and Shapiro, J (1968). A clinical and physiologic study of grain handlers. Archives of Environmental Health, 16, 380-384.

Opie, E C (1924). Desensitisation to local action of antigen (Arthus Phenomenon). Journal of Immunoloy, 9, 247-253.

Paisley, D P G (1969). Isocyanate hazard from wire insulation, an old hazard in a new guise. British Journal of Industrial Medicine, 26, 79-81.

Pepys, J, and Hutchcroft, B J (1975). Bronchial provocation tests in etiologic diagnosis and analysis of asthma. American Review of Respiratory Disease, 112, 829-859.

Pepys, J, Pickering, C A C, Breslin, A B X, ando Terry, D S (1972). Asthma due to inhaled chemicalo agents-tolylene diisocyanate. Clinical Allergy, 2, 225-236.

Pickering, C A C, Moore, W K S, Lacey, J, HolfordStrevens, V C, and Pepys, J (1976). Investigation of $\omega$ a respiratory disease associated with an air- $\overrightarrow{0}$ conditioning system. Clinical Allergy, 6, 109-118.

Plessner, M M (1960). Une maladie des trieurs de $\vec{\omega}$ plumes: la fièvre de canard. Archives des Maladies Professionelles, 21, 67-69.

Schilling, R S F (1956). Byssinosis in cotton and other textile workers. Lancet, 2, 261 and 319.

Schoenberg, J B, Mitchell, C A (1975). Airway disease $\omega$ caused by phenolic (phenol-formaldehyde) resinc exposure. Archives of Environmental Health, 30, 574-577.

Siracusa, A, Curradi, F, and Abbritti, G (1978). Re- current nocturnal asthma due to tolylene di- isocyanate: a case report. Clinical Allergy, 8, 195-

Sokol, W N, Aelony, Y, and Beall, G N (1973). Meat $-\vec{\theta}$ wrapper's asthma. Journal of the American Medical. Association, 226, 639-641.

Williams, N, Skoulas, A, and Merriman, J E (1964). Exposure to grain dust I. A survey of the effects. Journal of Occupational Medicine, 6, 319-329.

Wright, B M, and McKerrow, C B (1959). Maximum forced expiratory flow rate as a measure of ventila- $\mathrm{Q}$ tory capacity. British Medical Journal, 2, 1041- $\overline{\overline{0}}$ 1047.

Requests for reprints to: Dr P S Burge, Departmento of Clinical Immunology, Cardiothoracic Institute, Brompton Hospital, Fulham Road, London SW3 6HP. 